\title{
Comparison of Innovative Talent Cultivation Pattern in America and China
}

\author{
Ren Jinluan \\ School of Economics \\ and Management \\ Communication Univ. \\ of China \\ Beijing, China \\ jinluan_ren@163.co
}

$\underline{\mathrm{m}}$

\author{
Liu Lihua \\ School of Economics \\ and Management \\ Communication Univ. \\ of China \\ Beijing, China \\ lhliu@cuc.edu.cn
}

\author{
Liu $\mathrm{Hu}$ \\ School of Economics \\ and Management \\ Communication Univ. \\ of China \\ Beijing, China \\ $\underline{\text { liuhu@cuc.edu.cn }}$
}

\author{
Yan Mengmeng \\ School of Economics \\ and Management \\ Communication \\ University of China \\ Beijing,China \\ mengmeng2791@12 \\ 6.com
}

\author{
Zhang Qian \\ School of Economics \\ and Management \\ Communication \\ University of China \\ Beijing,China \\ haiqianqianer@163.c
}

\begin{abstract}
Independent innovation has become a very important strategy for China to construct a innovation country. We need to cultivate and train a large number of innovative talents. This paper compares and analyzes Chinese innovative talents cultivation pattern with American, finds out some of our shortcoming, and proposes some countermeasures and suggestions for training top-notch innovative talents.
\end{abstract}

\section{Keywords-Innovative Talents; Cultivation pattern; Comparative study}

\section{BACKGROUND}

With the development of creative industries, the innovative talent cultivation has become a world attention problem. In order to improve the quality of talent cultivation, our country has adopted a series of methods. In the long history of Chinese Education, the study and practice on innovative talent cultivation is of long standing. From the "Education Program of Young Children to Study Abroad" in the end of the Qing Dynasty to "Elite Classes in University of Science and Technology of China" experiments since 1978, our country has accumulated much valuable experience for study. Chinese scholars have also carried out a number of innovative talents cultivation research. Liu Jianping put forward that lead the growth of a high-quality of top-notch innovative personnel by high level of teaching faculty, provide favorable conditions for enhancing students' creative ability and practical ability by high level of discipline platform, upgrade students' overall qualities by high level of education and teaching, promote students' comprehensive development, broaden students' global vision by high level of international cooperation and exchange, etc [1]. Chang Weiya, etc. proposed that we need to establish new concept of teaching management and new model of teaching management, to explore new methods of teaching management, teaching management departments should gradually change from management type to research, education and service type in order to achieve the goal of innovation talent training[2]. Liu Bing, etc. suggested that we should reform our teaching methods in order to cultivate innovative talents [3].

As a science and technology highly developed country in the world, the United States of America's Innovative Talents

Funded by: Beijing Education Science $11^{\text {th }}$ Five-Year Planning Project for 2009 Youth Special Issue: Cultivation Pattern of Creativity Talents (Project No. CDA09053)
Cultivation Pattern has become the focus of attention American scholars have done a lot of research on inovative Talents Cultivation. McDonough, etc. surveyed of 1,188 American colleges and universities in 1987, and 6\% of them offering creativity courses [4]. Qualitative study conducted by Cole, etc. in 1999, examined classroom environment where in favor of developing students' creativity. The study found that the relationship between teachers and students, the assessment methods which do not stress uniform standard, and encouraging thought in multiple perspectives are very important to create a creative atmosphere [5]. Fasko researched on relationship between creativity and education from pre-school age until the ages of 16 students at the public schools in the United States. The scholars Summarized creative thinking pattern (such as Guilford, 1985; Renzulli, 1992; Runco \& Chand, 1995), and technical methods to develop creativity (such as Davis, 1982; Sternberg \& Williams, 1996). Some studies pointed out that there are link between creativity and learning (such as Karnes et al, 1961; Torrance, 1981)[6]. Cropley, etc. (2000) tried to let engineering undergraduate to draw innovative ideas more easily by teaching creativity. In Sternberg's (2004) book, he discussed what creativity is, what kind of person possesses creativity, and whether there is any evidence to prove that creativity is domain-specific or general areas. Decades of experiments and studies probed the methods to promote creative thinking of adults and children in schools, businesses and research industry (Parnes, 1992) [7]. Eikhof and Haunschild (2006) connected the research on lifestyle with innovation industry, opened up a new research perspective of the creativity and innovation management, and they believed that the artists in creative industries should solve the conflict on the need for self-management between artistic work and economic [8]. Jackson etc. (2006) thought that college graduates who may face a complex world are required to be flexible, adaptable, independent and innovative [9].

\section{CUlTIVATION PHILOSOPHY AND METHODS OF AMERICAN INNOVATIVE TALENTS}

\section{A. Individuation philosophy}

Personalized education has long been the main theme of the American educational development. The United States attaches importance to comprehensive personal development and self-realization, and puts the personality cultivation in the first place. The training objectives of American higher 
education are realized by the teaching system, for example, credits can be accumulated, stored and transferred, and can circulate in various disciplines, institutions or even universities within certain number of years. These institutions promote to form a healthy competition among all colleges and universities [10].

\section{B. Student-centered philosophy}

Since 1990s, American Universities have been carring on education innovation continuously, adhere to one "center" and three "combination", that is student-centered, combination of intracurricular and extracurricular, science and humanities, teaching and research, formed a unique innovative talents cultivation pattern gradually[11] In October 1998, the American University pioneered the philosophy of "student-centered", the philosophy was written in the declaration of the international conference on higher education by UNESCO. "Declaration" pointed out: "in the rapidly changing world now, obviously higher education needs new perspective and new pattern as student-centered", required "policy-makers or decision makers in a country or colleage and university to focus in students and their needs, and regard students as the main and responsible participants in the reform of higher education. This should include that the students participate in discussions about higher education issues, involve in the assessment, participate in the reform of the curriculum and pedagogy, and participate in the formulation of policies and university management within in the current system [12].

\section{Pedagogy of "three combination"}

"Three combination" pedagogy are adopted by university.

1) combination of Intracurricular and extracurricular. University in America pay attention not only to classroom teaching, but more emphasize on extra-curricular practice, intracurricular and extracurricular closely combined. Classroom teaching is very flexible, and the environment of the classroom teaching is relaxed. In order to develop students' ability, teachers use a variety of teaching methods, such as lectures, discussions, experiments, role-playing, case studies, simulation, self-study and so on. In this way, students have the largest room to expand ability. Teachers implement heuristic teaching, interact with students, teach in and learn from the classroom simultaneously, and fully mobilize students' enthusiasm and initiative in the study. Meanwhile these methods impel teachers to improve their knowledge structure continuously, and elevate their teaching and research ability ceaselessly.

In American universities, entrepreneurship has become an important element in campus culture. In 1999, 1,100 colleges and universities in the United States have offered entrepreneurship training courses. According to a survey, $37.6 \%$ of university offered entrepreneurship courses in the undergraduate program, $23.7 \%$ of university offered entrepreneurship courses in graduate program, $38.7 \%$ of university offered this kind of courses in undergraduate or graduate program.
2) Combination of science and humanities. Both inside and outside the classroom, American University emphasize on science education, also attaches great importance to humanities education, pay more attention to the unification of both. "investigation report on curriculum of Harvard" proposed in April 2004, all Harvard undergraduates should be subject to a certain depth and breadth of natural science education as learning humanities and social sciences. In addition, the quantitative reasoning sourses required to be part of the general education for all students. Students should select one course at least which has obvious quantitative reasoning component.

Strengthening science education, of course, is very important, the humanities education also can not be ignored. Stanford requires all undergraduate learning introduction to humanities course for one year. From the specific content for each course of Introduction to Humanities, despite their focus may be different from each other, but almost each course emphasizes on presenting one after another question for student to discuss, and integrates literature, history, philosophy knowledge in one course as far as possible. Either Harvard or Stanford, or other universities in the United States, their interdisciplinary curriculum, more often combined humanities education and science education.

3) Combination of teaching and research. In American universities, the combination of teaching and research not only means the teaching to be combined with teachers' research, but the teaching combined with the students' research. U.S. colleges and universities focus on introducing scientific research into students' practice, trying hard to connect practice with scientific research closely. In U.S. universities, comprehensive practice course are generally set up for students to explore the world, students are organized to participate in scientific research activities. Undergraduate students who have the opportunity to participate in research and standing on the forefront of new knowledge, is the most obvious competitive advantage in the best American universities in undergraduate education.

Currently, almost all research universities have established undergraduate research program, some universities also offers a variety of undergraduate research programs [13]. Undergraduate research activities have now expanded to more students and more disciplines, not only senior students but also junior students, not only polytechnic, medical and agricultural students, but liberal arts students to participate.

\section{Curriculum system under complete credit system and flexible innovative courses}

The credit system in American University gives students freedom to study at the largest extent. As long as students completed the required compulsory courses, they can choose any other elective courses according to their own interests, expertise and learning situation within a certain range. Students have a great degree of freedom to select courses, 
and they are allowed to choose courses inter-department, interdisciplinary or even inter-university. The system is conducive to the diversification of student's knowledge structure, and also conducive to the knowledge penetrate between the disciplines and the development of interdisciplinary. As a result, it promotes to cultivate a personalized student to adapt to the changes in human resource market demand. Students do not have to shape themselves in a fixed pattern. They can enjoy maximum autonomy and initiative in learning, and give full play to the potential and expertise to get what they want.

Innovation theory courses offer in many universities. American university pay attention to carry out innovative theoretical education, set "innovative principle", "innovative design" or some similar courses, establish the appropriate mechanisms to encourage teachers to give lectures associated innovation. Early in the 1950s, Harvard put "creation science" as foundation course. Various American universities have generally offerd some courses like "Creation", "creativity development", and so on, they also apply the system theory of creative thinking to modify the teaching contents of more than 200 professional courses in verious disciplines of engineering, science, art, and management. At the same time, the U.S. military, political authorities and the public enterprises also offer training courses for creative thinking, hence formed a better innovative education system.

\section{E. Scientific assessment methods to guide higher education to take the road of innovation}

The qualification and performance of American University are assessed by a third party of educational assessment agency. The evaluation criteria mainly depend on the university positioning accuracy, reasonable disciplinary orientation, school characteristics distinctive, and the degree the graduates meet the market demand. This kind of assessment system ensures the fairness, scientificalness and objectivity of assessment, which guide and promote to improve the innovative educational mechanism.

\section{COMPARISON OF INNOVATIVE TALENT CULTIVATION PATTERN BETWEEN CHINA AND THE UNITED STATES}

There are many differences in innovative talent cultivation between China and the United States, which are mainly reflected in the following aspects. First, there are differences on the fund investment. The investment in innovation talent nurturing research funding is too low in China, while there are a variety of names of American investment in innovation funding, such as establishing innovative training center, providing innovative research funding for teachers and students, providing educational innovation awards, etc. Second, the differences of cooperation on universities and enterprises existed between China and the United States. American universities have close cooperation with enterprises, and enterprises provide appropriate funding for the university's innovation talent training, which made a high degree of integration of research resources. While the relationships between Chinese universities and enterprises is not enough on innovative talent cultivation, and the actual gap between research and production is widespread. Third, environment of innovation culture is different. Our schools generally lack the cultural environment to encourage innovation, while the large number of schools in the United States offered the general education courses and humanities courses in order to form a kind of inclusive, balanced and innovative campus culture. Fourth, there are differences on cultivating overall quality of creative talents. Chinese universities pay insufficient attention to the knowledge of the structure of students, the structure of ability and personality traits. However, American university stressed to provide student with innovative consciousness, innovative spirit and innovative ability and so on, on the basis of comprehensive development, emphasizing the free development of the personality. Fifth, the teaching methods are different. Teachers in Chinese schools have basically adopted the traditional cramming teaching methods, emphasized on imparting knowledge, neglected of students' ability, particularly creative ability, and focus only on the knowledge for student to remember rather than focus on the development of their comprehensive quality and innovation capacity. In the relationship between teaching and learning, there is too much emphasis on the function of teacherleading. Teachers impart knowledge into students one-way, and students learn passively, which the subjectivity of students be greatly inhibited. These methods limited the personal development, and to a large extent restricted the play of the students' innovative spirit and creative ability. However, American cultivation of innovative talents integrate the needs of today's society on creative talents into the all-round development of education philosophy, which is characterized by inspiring students' potentiality to adapt to various environmental, develop their independence, teamwork, creating ability and leadership qualities. Sixth, the government education system is different. In U.S., government provides a flexible and open education system, giving a high degree of autonomy to Colleges and Universities. Ministry of Education and Higher Education Commission play a coordinating role in higher education affairs. But the Chinese government pays more emphasis on patterning, standardizing and uniform. Seventh, differences exist in cultivate systematized. The United States has formed a system of universities, governments, businesses and nongovernmental organizations that collaborate to nurture creative talents, while the situation is relatively split between the various departments of China.

\section{SUGGESTION ON THE CULTIVATION OF INNOVATIVE TALENTS IN CHINA}

In the innovative talents cultivation, we need to modify our cultivation philosophy and training pattern on innovative talents, reform our evaluation system of education quality and talent assessment criteria, create new teaching methods, and exploring a variety of cultivation methods. Specific recommendations are as follows.

1) Cease the division of arts and sciences in high school. The abolition of the division can provide students more opportunity to learn a variety of knowledge, and be able to 
expand their expertise at university based on their own interests.

2) Reform the entrance examination system. Reform undergraduate enrollment system to provide innovative talents smooth channel, otherwise it is hard to cure the ills of the "examination-oriented education".

3) Reform the teaching operation and management mechanisms. We should form a student-centered philosophy and serve for the students. Our teaching operation and management mechanism should assure the credit system and flexible educational system, and provide an institutional guarantee for students to learn independently and creatively.

4) Reform the teaching evaluation mechanism. The scoring scheme of course implement the separation of teaching and examination, and combine with quizzes, class discussion and final examination. Schools should strengthen the management of examination, promoting the construction test database. Introduce the incentive and competition mechanism, progressively implement the system of teachers competition in teaching and students electing teachers independently.

5) Improve the quality of teachers. To create innovative talents, teachers themselves should have sense of innovation and creativity. The sense of innovation and innovative capacity of teachers, and the overall quality, ability and level of the faculty directly determine the quality of student. Only a high quality of faculty can lead the growing up of creative talents.

6) Reform curriculum system. Increase the number of elective courses and general education courses to encourage students to choose courses freely based on their professional interest, strengthen the cross and integration of different disciplines, and develop comprehensive and integrated talents. Offer courses or seminars on innovation so that students can know what creative thinking is and how to cultivate this habit of thinking. Establish innovative education fund and special experimental research funds, to provide the necessary financial support for innovative educational activities to students and teachers.

7) Improve teaching methods. In university education, strengthen reading intensity and encourage students to think, to enable students to truly become the main body of study and teachers become the organizers and guidance of classroom. Emphasis on case teaching, practice teaching, and establish a practice base in order to provide students with a platform for innovation and opportunity.

8) Make close ties to strengthen teaching, research and production practices. Universities should strengthen cooperation with enterprises and research institutions, stimulate students' interest in learning and elevate students' innovating ability in the practice of scientific research and production. By means of combination teaching with producing, students both deepen the understanding of the course and master the preliminary scientific research method.

It is a good way to study foreign experience, reform and improve our cultivation philosophy, methods and means on innovative talents. We must be realistic in our self-estimation, neither being conceited nor belittling ourselves. Carring forward our own advantages, integrating the essence of Chinese and foreign education mode, educational philosophy and education methods, China will become a real talent power country.

\section{REFERENCES}

[1] Jianping Liu, "Construction cultivating system of high quality of topnotch innovative talents", Chinese higher education, 2008 (01): 26-28

[2] Weiya Chang, Li Zhao, "Setting up new idea of teaching management to the innovative talents training", Chinese higher education, 2008 (03): $48-49$

[3] Bing Liu, Wei Chen, "Reform of teaching method and cultivation of innovation talents", China Education Innovation Herald, 2007: 3334

[4] McDonough, Peter; McDonough, Bernadette, "A Survey of American Colleges and Universities on the Conducting of Formal Courses in Creativity”, Journal of Creative Behavior, vol. 21, 1987 (4): 271-282

[5] Darnell G. Cole, Heather L. Sugioka, Lisa C. Yamagata-Lynch, "Supportive Classroom Environments For Creativity in Higher Education", The Journal of Creative Behavior, vol. 33, 1999 (4): 277 293

[6] Daniel Fasko, "Education and Creativity", Creativity Research Journal, vol. 13, 2001, (3\&4): 317-327

[7] Robert J. Sternberg, Elena L. Grigorenko, Jerome L. Singer, "Creativity: From potential to realization", American Psychological Association (APA), 2004

[8] Doris Ruth Eikhof, Axel Haunschild, "Lifestyle Meets Market: Bohemian Entrepreneurs in Creative Industries", Creativity and Innovation Management, Vol. 15, 2006(3): 234-241

[9] Norman Jackson, Martin Oliver, Malcolm Shaw, James Wisdom, “An Imaginative Curriculum", Routledge, 2006

[10] Xuelian Gao, "Enlightenment of foreign innovative talents training mode to Chinese higher education reform", Higher Agricultural Education, 2007(1 1): 85-87

[11] Xiaopeng Zhang, "Analysis of American college of innovative talents training mode ", China University Teaching, 2006(3): 7-11

[12] Keyong Cai, "Regarding students' development as the basic ideal", Research in higher education, 2000 (5)

[13] Boyer, "The Commission on educating Undergraduate in the Research University, Reinventing Undergraduate Education: Three Years After the Boyer Report.", http://www.sunysb.edu/press/021006boyer. 